\section{Bank backs Indian AIDS program again}

The Indian government has announced \$326.3 million funding for the second phase of the country's AIDS control program between now and 2004. Although the first phase, which used an \$87 million loan from the World Bank, ended in March without affecting on the country's AIDS situation, the Bank has more than doubled its loan to $\$ 191$ million. The new project is also assisted by $\$ 41.5$ million from the US Agency for International Development (USAID), \$45 million from the British Department for International Development (DFID), and \$10 million from the United Nations Program for AIDS (UNAIDS). The remaining \$38.8 million will come from the Indian health budget.

According to National AIDS Control Organization (NACO) program director J.M.R. Prasada Rao, the new program is a "paradigm shift" in that it is completely decentralized from NACO and gives autonomous control to each state. And whereas earlier efforts focused on creating AIDS awareness, the new project will translate this into behavioral change in high-risk groups. Ten modern blood banks are being built and twenty are being upgraded. AZT prophylaxis will be offered to all HIV-positive pregnant mothers.

NACO predicts that by 2000 , five million Indians will be infected with HIV, and AIDS deaths will reach more than half a million per year in 2010. But although the project aims to ensure that less than 1 in every 100 Indians in the reproductive age group is infected with HIV by 2004, this goal does not include the States of Andhra Pradesh, Karnataka, Manipur and Tamil Nadu where the prevalence is already as high as 2.4 percent. The goal here is to restrict the spread of the infection to less than 3 percent.

Finally, AIDS researchers who were promised $\$ 50$ million for vaccine development (Nature Med. 4, 750; 1998) are disappointed, as only $\$ 1$ million has been earmarked for this purpose. K. S. Jayaraman, New Delhi

\section{Few state tobacco dollars to go to control}

The American Heart Association (AHA), the Centers for Disease Control and Prevention (CDC) and the Campaign for Tobacco-Free Kids are pressuring State legislators to spend more of the money that each will receive from the national tobacco settlement on funding tobacco control measures. Many States propose to spend the money on education, roadbuilding, and New York may spend \$8 million on improving its Buffalo Zoo. Others have chosen to support biomedical research (Nature Med. 5, 10; 1998).

According to a new report by the AHA and the campaign, only six of the 27 States that have passed legislation have committed to control programs at levels recommended by the CDC, which advises that 25 percent of settlement funds to go to CDC-sanctioned control programs. CDC "Best Practice" control guidelines include chronic disease programs such as cancer registries, education and countermarketing efforts.

Six states have made no commitment to tobacco control, and although ten others say they will earmark funds for this activity, the report claims that they will spend only a fraction of what the CDC has urged.

One of the six states with no stated intentions of funding control measures is Michigan, which has earmarked 25 percent of its settlement funds for a biomedical research cooperative between the University of Michigan, Michigan State and Wayne State University, and a private organization, the Van Andel Institute. But this action is also being criticized as irrelevant to the main goal-stopping tobacco use before it starts.
Although the campaign backs biomedical research, "It's not what we want to see them do with the tobacco money," says spokesman Joel Spivak. The American Lung Association also "wants to see a significant portion of the settlement go to cessation, education and prevention programs" and would not comment directly on the appropriateness of putting settlement dollars into research.

John Banzhaf, executive director of Action on Smoking and Health, says 25 percent isn't enough and his group wants the settlement overturned on the grounds that it will do nothing to stop tobacco use. In the event that it proceeds, he says money should not be spent on roads or even biomedical research: "The settlement grew out of, and is designed to compensate for injuries caused by tobacco, so as valuable as these things are in the abstract, they have nothing to do with tobacco."

Last month, the CDC issued new guidelines on how states can implement tobacco control plans, noting that tobacco use causes more than 430,000 US deaths per year. The agency estimates, based on each state's smoking rate and settlement share, that states need to spend a total of $\$ 8-21$ billion over the next five years to put "effective" control programs in place.

And as of yesterday, the CDC began distributing $\$ 50$ million between states for tobacco control efforts. Forty-six states reached a tobacco settlement agreement on 23 November 1998, worth \$206 billion over the next 25 years.

Alicia Ault, Washington D.C.

\section{Busquin appointed European research Commissioner}

As Nature Medicine went to press, physi- strong Commission not to receive a favorcist Philippe Busquin was preparing to be able report after questioning by the Eurosworn in as Commissioner of DG12, to be renamed the Research Directorate, of the European Commission. He replaces Edith Cresson, about whom allegations of corruption brought the Commission to its knees in March this year.

Busquin, who began a political career as a socialist in 1977

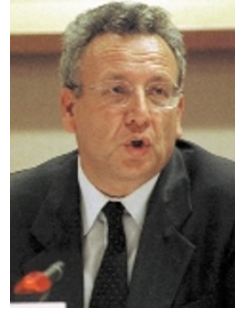

Philippe Busquin pean Parliament at the start of September, Busquin will oversee the Fifth Framework Budget which totals EUC15 billion (US\$15.5 billion). The Budget includes several biomedical research programs such as EUC190 million for 1998-2002 for study of the aging population; EUC300 million for infectious diseases and EUC1280 department of the Free University of Brussels, has been accused of having little experience of science policy for the past two decades. The only member of the 19 million for improving human research potential and the socio-economic knowledge base.

KaREN BirMinghaM, LONDON 